\begin{tabular}{|c|l|}
\hline Title & Polycyclic A romatic Compounds mediated Electrochemical Reduction of A Ikyl Mesylates \\
\hline Author(s) & Senboku, Hisanori; Takahashi, Megumi; Fukuhara, Tsuyoshi; Hara, Shoji \\
\hline Citation & $\begin{array}{l}\text { Chemistry Letters, 36(2), 228.229 } \\
\text { https://doi.org/10.1246/1.2007.228 }\end{array}$ \\
\hline Issue Date & 2007-02-05 \\
\hline Doc URL & http://hdl.handle.net/2115/70907 \\
\hline Type & article \\
\hline File Information & cl.2007.228.pdf \\
\hline
\end{tabular}

Instructions for use 


\title{
Polycyclic Aromatic Compounds-mediated Electrochemical Reduction of Alkyl Mesylates
}

\author{
Hisanori Senboku, ${ }^{*}$ Megumi Takahashi, Tsuyoshi Fukuhara, and Shoji Hara \\ Laboratory of Organic Reaction, Division of Chemical Process Engineering, Graduate School of Engineering, \\ Hokkaido University, Sapporo 060-8628
}

(Received October 30, 2006; CL-061275; E-mail: senboku@eng.hokudai.ac.jp)

\begin{abstract}
Electrochemical reduction of alkyl mesylates was successfully carried out by using an undivided cell equipped with a Pt cathode and an $\mathrm{Mg}$ anode in the presence of biphenyl and $t$ - $\mathrm{BuOH}$. The reaction could proceed efficiently under mild conditions to give the corresponding alkanes in moderate to good yields. This procedure could also be applicable to chemoselective reduction of mesylates having functional groups such as epoxide, olefin, acetal, hydroxy, or cyano groups.
\end{abstract}

Reduction of alcohols to the corresponding alkanes is an important transformation in organic synthesis. ${ }^{1-3}$ One of simple and useful methods involves conversion of hydroxy groups to the corresponding alkyl sulfonates, such as tosylates or mesylates, followed by reduction with hydride. As a hydride reagent, $\mathrm{LiAlH}_{4}{ }^{4}$ or $\mathrm{LiBEt}_{3} \mathrm{H}^{5,6}$ is frequently used for this aim. Their high reactivity, however, sometimes causes serious troubles such as over-reduction of other functional groups in the substrates. Therefore, chemoselective and widely applicable reduction of alkyl sulfonates under mild conditions would be still desirable although several alternative methods for the reduction of alkyl tosylates or mesylates have been developed. ${ }^{7-13}$ On the other hand, electrochemical process can reduce various organic compounds under neutral and mild conditions. ${ }^{14}$ While electrochemical reduction of alkyl tosylates predominantly gave the corresponding alcohols, ${ }^{15}$ a similar reduction of alkyl mesylates gave the corresponding alkanes. Thus, electrochemical reduction of alkyl mesylates could take place efficiently by using a divided cell equipped with a lead cathode and a platinum anode to give the corresponding alkanes in good yields. ${ }^{12}$ It was also reported that mesylates of $\alpha$-hydroxy esters could be reduced to the corresponding esters by indirect electrochemical reduction using diphenyl diselenide in a divided cell. ${ }^{13}$ Although both electrochemical reactions could proceed under neutral and mild conditions to give the products in good yields, use of unfavorable metal as an electrode and a complicated divided cell could not be satisfactory from the view points of environmentally friendly organic synthesis. We tried electrochemical reduction by using a simple and easy-handled undivided cell equipped with a platinum cathode and a magnesium anode, and found that electrochemical reduction of alkyl mesylates could proceed efficiently in the presence of polycyclic aromatic compound such as naphthalene and biphenyl as an electron-transfer mediator to give the corresponding alkanes in moderate to good yields. In this communication, we wish to report polycyclic aromatic compounds-mediated electrochemical reduction of alkyl mesylates using an undivided cell.

A constant current electrolysis of a DMF solution of dodesyl mesylate 1a containing $0.1 \mathrm{M} \mathrm{Bu}_{4} \mathrm{NBF}_{4}$ using an undivided cell equipped with a platinum plate cathode and a magnesium rod anode gave a 35:65 mixture of dodecane 2a and 1-dodecanol. Therefore, we tried the electrolysis in the presence of polycyclic aromatic compounds as an electron-transfer mediator. Other than benzene and toluene, we found naphthalene, phenanthrene, and $m$-terphenyl were effective for yielding 2a selectively. Better results were obtained when the electrolysis of 1a was carried out in the presence of biphenyl which exclusively gave 2a in $62 \%$ yield under the reaction conditions described in eq 1 (Conditions A). Biphenyl could be recovered quantitatively after the reaction and the recovered biphenyl could also be reused as a mediator.

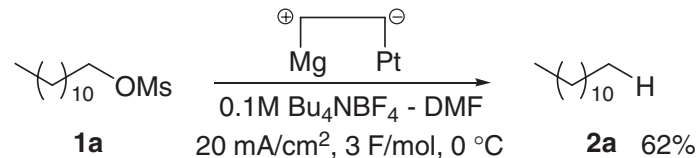

$$
\begin{aligned}
& \text { biphenyl (4 equiv.) }
\end{aligned}
$$

During continuous study on scope and limitation of the present reaction using functionalized substrates, it was found that this reaction system was also applicable to the substrate having a hydroxy group ${ }^{16}$ (See below). Then, we tried the electrolysis in the presence of a proton source and the results are summarized in Table 1. As the best result, electrochemical reduction of mesylate 1a in the presence of biphenyl (4 equiv.) and $t-\mathrm{BuOH}$ (10 equiv.) with $8 \mathrm{~F} / \mathrm{mol}$ of electricity gave $\mathbf{2 a}$ in $74 \%$ yield (Entry 7 in Table 1) (Conditions B). It is also noted that in this case, biphenyl could also be recovered in quantitative yields.

Electrochemical reduction of various alkyl mesylates $\mathbf{1}$ was carried out under "Conditions A (in the presence of biphenyl with $3 \mathrm{~F} / \mathrm{mol}$ of electricity) and $\mathrm{B}$ (in the presence of biphenyl and $t-\mathrm{BuOH}$ with $8 \mathrm{~F} / \mathrm{mol}$ of electricity), $" 17$ and the results are summarized in Table 2 . The present reaction was also effective

Table 1. Effect of an additive ${ }^{a}$

\begin{tabular}{|c|c|c|c|c|}
\hline Entry & $\begin{array}{l}\text { Additive } \\
\text { (equiv.) }\end{array}$ & $\begin{array}{l}\text { Electricity } \\
/ \mathrm{F} \mathrm{mol}^{-1}\end{array}$ & $\begin{array}{l}\text { Yield }^{\mathrm{b}} \\
/ \%\end{array}$ & $\begin{array}{c}\text { Recovered } \mathbf{1 a} \\
/ \%\end{array}$ \\
\hline 1 & none & 5 & 59 & 0 \\
\hline 2 & $t$-BuOH (2) & 5 & 62 & 0 \\
\hline 3 & $t-\mathrm{BuOH}(4)$ & 5 & 64 & trace \\
\hline 4 & $t$-BuOH (10) & 5 & 61 & 17 \\
\hline 5 & $t$-BuOH (20) & 5 & 57 & 20 \\
\hline 6 & $t-\mathrm{BuOH}(50)$ & 5 & 56 & 28 \\
\hline 7 & $t-\mathrm{BuOH}(10)$ & 8 & 74 & 0 \\
\hline 8 & $i-\mathrm{PrOH}(10)$ & 8 & 66 & trace \\
\hline 9 & $\mathrm{EtOH}(10)$ & 8 & 37 & 42 \\
\hline $10^{\mathrm{c}}$ & $\mathrm{H}_{2} \mathrm{O}(10)$ & 8 & 61 & 15 \\
\hline
\end{tabular}

${ }^{\mathrm{a}} \mathrm{A}$ constant current electrolysis $\left(20 \mathrm{~mA} / \mathrm{cm}^{2}\right)$ of $\mathbf{1 a}(1 \mathrm{mmol})$ in DMF $(16 \mathrm{~mL})$ containing $0.1 \mathrm{M} \mathrm{Bu}_{4} \mathrm{NBF}_{4}$ was carried out in the presence of biphenyl (4 equiv.) at $0{ }^{\circ} \mathrm{C}$. ${ }^{\mathrm{b}}$ Isolated yield. ${ }^{\mathrm{c}} 1$-Dodecanol was obtained in $4 \%$ yield. 
Table 2. Electrochemical reduction of alkyl mesylate $\mathbf{1}^{\mathrm{a}}$

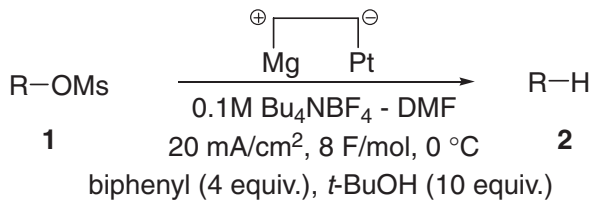

Entry

${ }^{\mathrm{a}} \mathrm{A}$ constant current electrolysis $\left(20 \mathrm{~mA} / \mathrm{cm}^{2}\right)$ of $\mathbf{1}(1 \mathrm{mmol})$ in DMF $(16 \mathrm{~mL})$ containing $0.1 \mathrm{M} \mathrm{Bu}_{4} \mathrm{NBF}_{4}$ was carried out at $0{ }^{\circ} \mathrm{C}$ in the presence of biphenyl (4 equiv.) and $t$ - $\mathrm{BuOH}(10$ equiv.) with $8 \mathrm{~F} / \mathrm{mol}$ of electricity. ${ }^{\mathrm{b}}$ Isolated yields. In parentheses, the yields in the reaction under Conditions A are shown.

for reduction of secondary alkyl mesylate $\mathbf{1 b}$ and cycloalkyl mesylate 1c (Entries 2 and 3 in Table 2). It is also noted that several functional groups were inert in this reduction system. Thus, electrochemical reduction of alkyl mesylates having epoxide, olefin, acetal, pivalate, hydroxy, or cyano group was also achieved in moderate to good yields without change of their functional groups (Entries 4-9 in Table 2). It is difficult to reduce mesylates $\mathbf{1 d}, \mathbf{1 g}$, and $\mathbf{1 i}$ to the corresponding alkanes $\mathbf{2 d}, \mathbf{2 g}$, and $\mathbf{2 i}$ without changing their functional groups, respectively when the reduction was carried out by using $\mathrm{LiAlH}_{4}$, a representative reducing agent.

Cyclic voltammetry of $\mathbf{1 a}$ and biphenyl was carried out. No reduction peak of $1 \mathrm{a}$ was observed at $>-3.2 \mathrm{~V}$ vs $\mathrm{Ag} / \mathrm{Ag}^{+}$ and a reduction peak of biphenyl appeared at ca. $-3.2 \mathrm{~V}$ vs $\mathrm{Ag} / \mathrm{Ag}^{+}$. On the other hand, cyclic voltammetry of biphenyl in the presence of $\mathbf{1 a}$ showed that the reduction current at $-3.2 \mathrm{~V}$ vs Ag/ $\mathrm{Ag}^{+}$increased when the amount of $\mathbf{1 a}$ increased. These results indicated that biphenyl would work as an electrontransfer mediator.

This work was financially supported by Grant-in-Aid for Scientific Research (C) (No. 15550082) from the Japan Society for the Promotion of Science.

\section{References and Notes}

1 S. W. McCombie, in Comprehensive Organic Synthesis, ed. by B. M. Trost, I. Fleming, Pergamon Press, 1991, Vol. 8, pp. 811833.

2 M. Yasuda, Y. Onishi, M. Ueba, T. Miyai, A. Baba, J. Org. Chem. 2001, 66, 7741.

3 a) V. Gevorgyan, J.-X. Liu, M. Rubin, S. Benson, Y. Yamamoto, Tetrahedron Lett. 1999, 40, 8919. b) V. Gevorgyan, M. Rubin, S. Benson, J.-X. Liu, Y. Yamamoto, J. Org. Chem. 2000, 65, 6179.

4 L. A. Paquette, in Encyclopedia of Reagents for Organic Synthesis, ed. by L. A. Paquette, John Wiley and Sons Ltd., Chichester, 1995, Vol. 5, pp. 3009-3014.

5 M. Zaidlewicz, H. C. Brown, in Encyclopedia of Reagents for Organic Synthesis, ed. by L. A. Paquette, John Wiley and Sons Ltd., Chichester, 1995, Vol. 5, pp. 3180-3183.

$6 \mathrm{LiEt}_{3} \mathrm{BH}$ generated in situ from $\mathrm{Et}_{3} \mathrm{~B}$ and lithium dimethylaminoborohydride was also applicable for the reduction of alkyl mesylates to the corresponding alkanes: S. Thomas, T. Huynh, V. Enriquez-Rios, B. Singaram, Org. Lett. 2001, 3, 3915.

7 Y. Fujimoto, T. Tatsuno, Tetrahedron Lett. 1976, 17, 3325.

8 F. Rolla, J. Org. Chem. 1981, 46, 3909.

9 Y. Ueno, C. Tanaka, M. Okawara, Chem. Lett. 1983, 795.

10 G. Radivoy, A. Alonso, M. Yus, Tetrahedron 1999, 55, 14479.

11 G. Radivoy, A. Alonso, Y. Moglic, C. Vitale, M. Yus, Tetrahedron 2005, 61, 3859.

12 T. Shono, Y. Matsumura, K. Tsubata, Y. Sugihara, Tetrahedron Lett. 1979, 20, 2157.

13 T. Inokuchi, T. Sugimoto, M. Kusumoto, S. Torii, Bull. Chem. Soc. Jpn. 1992, 65, 3200.

14 S. Torii, Electroorganic Reduction Synthesis, Kodansha Ltd., Tokyo, 2006.

15 P. Yousefzadeh, C. K. Mann, J. Org. Chem. 1968, 33, 2716.

16 There was a possibility that anion radical of biphenyl generated by one electron reduction would react with a proton source such as hydroxy group. Further one electron reduction followed by protonation would produce 1,4-dihydrobiphenyl, which could not work as an electron-transfer mediator.

17 General procedure for electrochemical reduction (Conditions B): A DMF solution $(16 \mathrm{~mL})$ of $\mathbf{1}(1 \mathrm{mmol})$, biphenyl (4 mmol), and $t$ - $\mathrm{BuOH}(10 \mathrm{mmol})$ containing $0.1 \mathrm{M} \mathrm{Bu}_{4} \mathrm{NBF}_{4}$ was electrolyzed at $0{ }^{\circ} \mathrm{C}$ with a constant current $\left(20 \mathrm{~mA} / \mathrm{cm}^{2}\right)$ under a nitrogen. Undivided cell equipped with a platinum plate cathode $\left(2 \times 2 \mathrm{~cm}^{2}\right)$ and a magnesium rod anode $(3 \mathrm{~mm} \phi)$ was used for electrolysis. After $8 \mathrm{~F} / \mathrm{mol}$ of electricity was passed, electrolyzed solution was acidified with $1 \mathrm{M} \mathrm{HCl}$ and then extracted with ether. The ethereal solution was washed successively with $\mathrm{H}_{2} \mathrm{O}$ and saturated brine. Dryness with $\mathrm{MgSO}_{4}$ followed by evaporation gave a crude product, which was purified by column chromatography with $\mathrm{SiO}_{2}$ to obtain 2. Biphenyl could also be recovered quantitatively. 